\title{
Methylmalonic Acidemia: Can Treatment be Improved?
}

\author{
Kimberlee Michals-Matalon ${ }^{1}$, Rachel Lombardo ${ }^{2}$, Kimberly Bilger ${ }^{3}$, Nancy Ross ${ }^{3}$, \\ Kelly Fuller ${ }^{4}$, Debra Freedenberg ${ }^{5}$ and Reuben Matalon ${ }^{6, *}$ \\ ${ }^{1}$ Department of Health and Human Performance Houston, University of Houston, TX, USA \\ ${ }^{2}$ School of Medicine, University of Texas Medical Branch, Galveston, TX, USA \\ ${ }^{3}$ Dell Children's Medical Center of Central Texas, Austin, TX, USA \\ ${ }^{4}$ Department of Pediatrics, Baylor Scott and White Memorial Hospital, Temple, TX, USA \\ ${ }^{5}$ Texas Department of State Health Services, Newborn Screening Branch, Austin, TX, USA \\ ${ }^{6}$ Department of Pediatrics, University of Texas Medical Branch, Galveston, TX, USA
}

\begin{abstract}
Methylmalonic acidemia (MMA) is a severe metabolic disorder, particularly with complete deficiency of methylmalonyl-CoA mutase. Dietary restriction has led to overt signs of deficiencies including skin rashes, hair loss, and poor growth. More liberal intake of the restricted amino acids has resulted in better growth and less frequent episodes of illness.
\end{abstract}

Keywords: MMA, hyperammonemia, carnitine, carglumic acid, newborn screen.

\section{INTRODUCTION}

In normal metabolism, methylmalonyl-CoA mutase degrades L-Methylmalonyl-CoA to Succinyl-CoA. Decreased activity of this enzyme, as seen in methylmalonic acidemia (MMA), causes the accumulation of methylmalonic acid in the body, with various detrimental effects as seen in Figure 1. MMA is a disorder of the metabolism of the amino acids isoleucine, methionine, threonine, and valine. Over $60 \%$ of confirmed cases of MMA are due to mutations in methylmalonyl-CoA mutase, and of these, $78 \%$ are mut mutations [1], with no residual enzyme activity.

The development and implementation of neonatal screening allows for the early identification of affected infants with MMA [2]. Patients with mut typically present within the first few days of life [3]. Typically, those with MMA mut have severe neurological manifestations of the disease [4].

The recommended treatment for MMA includes a low protein, high-energy diet in sufficient ratios to support normal growth and development [5]. However, emphasis is frequently placed on restriction of essential metabolites, leading to inadequate protein and energy intake, resulting in poor growth, hair loss, and skin rashes [6]. This case report demonstrates that adjusting dietary intake resulted with improved growth and fewer episodes of metabolic decompensation.

*Address correspondence to this author at the Department of Pediatrics, University of Texas Medical Branch, 301 University Boulevard, Galveston, TX 77555, USA; Tel: 409-772-3466; Fax: 409-772-9595;

E-mail: rmatalon@utmb.edu

\section{CASE REPORT}

The patient presented shortly after birth with acidosis and hyperammonemia, and then progressed to a semi-comatose state. At 3-4 days of age, a diagnosis of MMA was made and further study confirmed $m u t^{0}$. The baby improved after appropriate treatment and was discharged.

Initial long-term treatment was outlined as $0.5-0.7$ $\mathrm{g} / \mathrm{kg}$ natural protein. Medical food allowed $1.1 \mathrm{~g} / \mathrm{kg}$ of protein. Supplementation with $100 \mathrm{mg} / \mathrm{kg}$ levo-carnitine per day and 2.7-5.0 ml Bicitra per day (Sodium citrate $500 \mathrm{mg} /$ citric acid $334 \mathrm{mg}$ per $5 \mathrm{~mL}$ ). Caloric intake was about $100 \mathrm{cal} / \mathrm{kg}$, less than normal intake for a child this age. A G-button was placed for poor appetite and emergency feedings.

The patient was referred to our clinic at 3.5 years of age due to poor growth, hair loss, skin rashes, and frequent episodes of metabolic decompensation that required hospitalization. The metabolic episodes occurred at a frequency of 10-12 episodes per year. Height and weight were found to be less than $5^{\text {th }}$ percentile (Figures 2 and 3). The patient also had low blood concentrations of isoleucine, valine, leucine, and methionine. Arginine levels were consistently low, indicating over-restriction of amino acids. Further testing revealed low levels of pre-albumin and albumin.

The nutritional regimen was modified and the patient was placed on $1.2-1.5 \mathrm{~g} / \mathrm{kg} /$ day natural protein and $2.0-2.5 \mathrm{~g} / \mathrm{kg} / \mathrm{day}$ of medical formula, as well as $50 \mathrm{mg} / \mathrm{kg}$ levocarnitine, $50 \mathrm{mg} / \mathrm{kg}$ acetyl-carnitine and 


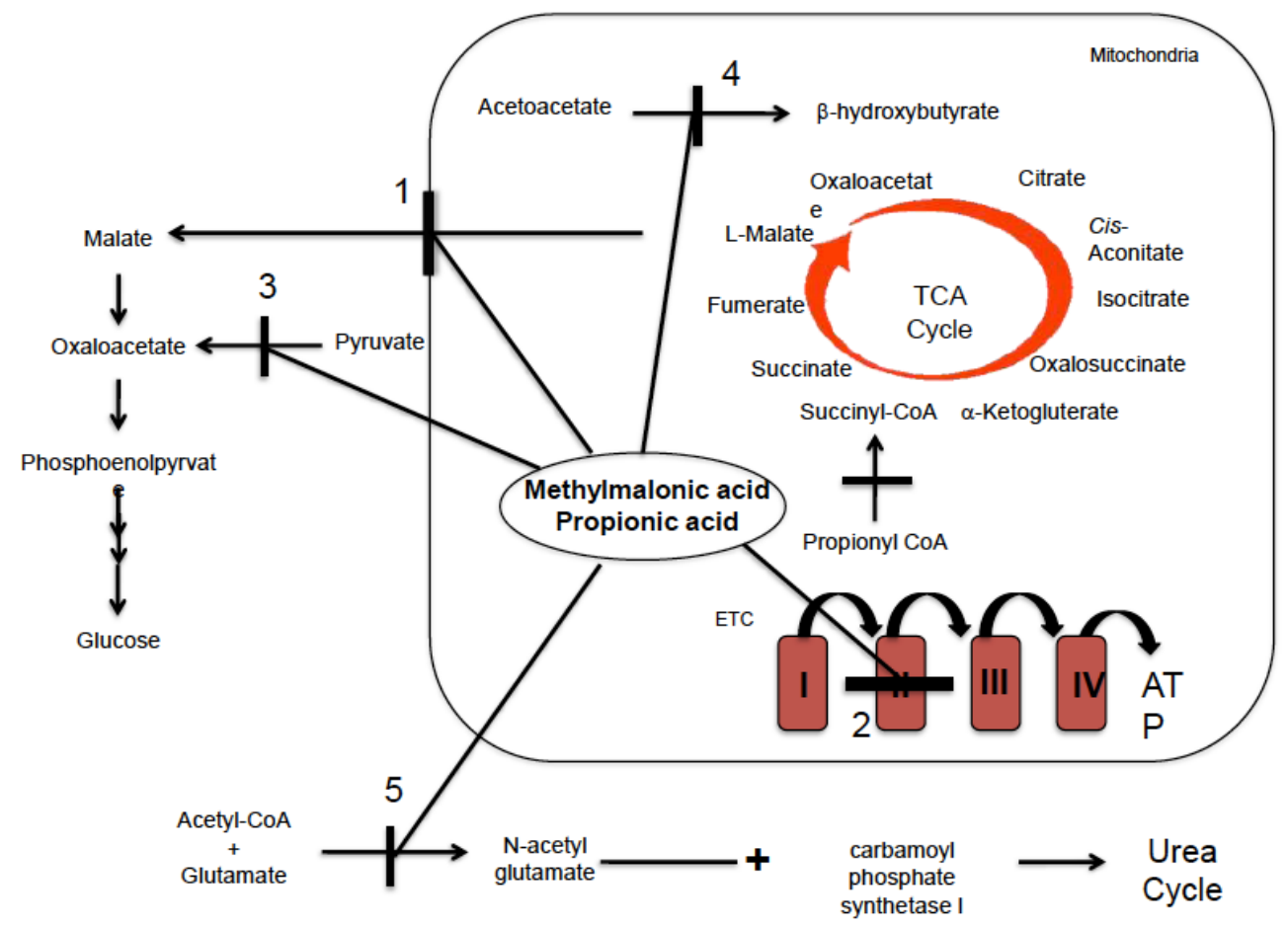

Figure 1: Biochemical pathway of methylmalonic acid in body.

\section{Height vs Age}

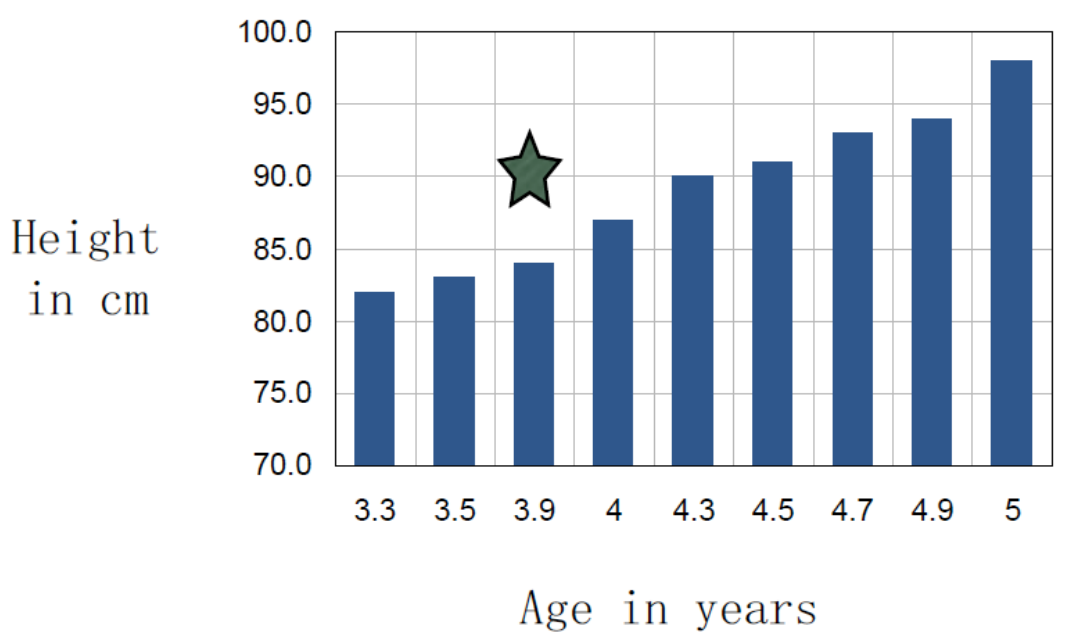

Figure 2: Depicts height versus age in this patient. Point of dietary change indicated by asterisks.

30-40 mL/day Polycitra K (Potassium citrate $1100 \mathrm{mg} / \mathrm{citric}$ acid $334 \mathrm{mg}$ per $5 \mathrm{ml}$ ). Daily caloric intake was increased to $130 \mathrm{cal} / \mathrm{kg}$. No other changes were made to the patient's dietary regimen.

\section{RESULTS}

Metabolites pre and post dietary changes are shown in Figure 4. The patient began to gain weight (Figure 3) and parents reported an improved energy level. In addition to improved growth, the patient experienced fewer episodes of metabolic acidosis, with no episodes requiring hospitalization, and was not hospitalized for two years following the adjusted dietary treatment.

\section{DISCUSSION}

Failure to thrive in patients with methylmalonic acidemia is common. The lack of adequate growth 


\section{Weight vs Age}

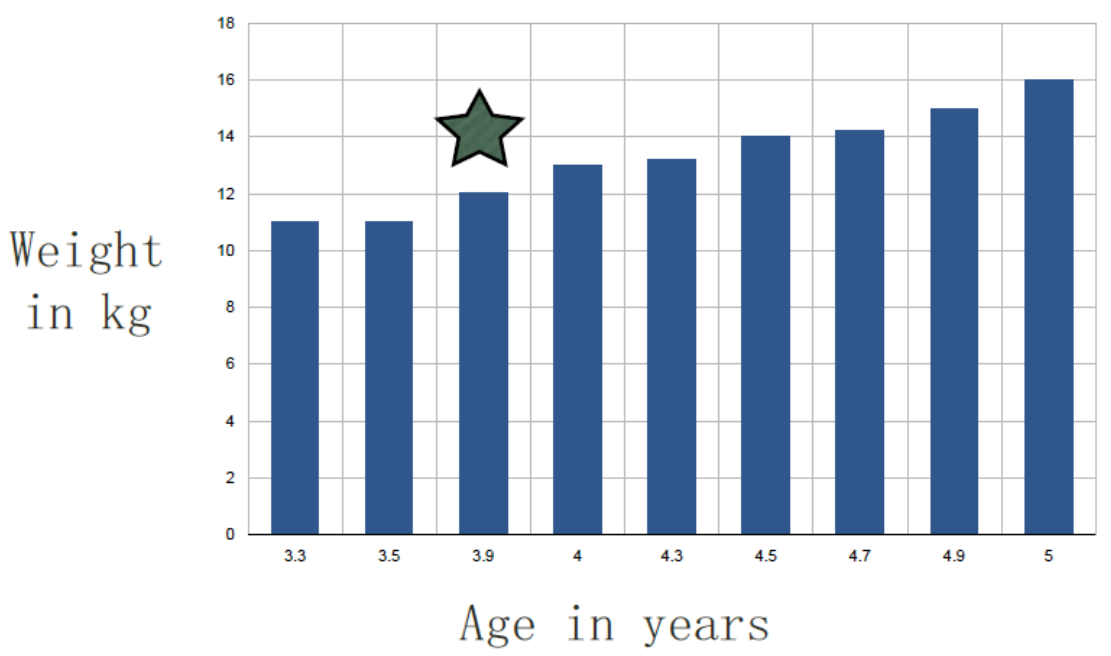

Figure 3: Depicts weight versus age in this patient. Point of dietary change indicated by asterisks.

\section{Metabolites Pre and Post Change in Diet}

Pre

- Albumin 3.5

- PreAlbumin 14.7

- Amino acids $\mu \mathrm{mol} / \mathrm{L}$

- Valine

30

- Isoleucine

12

- Leucine

169

- Meth

9

- Arginine

18

- Glycine

625

- Alanine

Figure 4: Metabolites pre and post dietary changes.

appears to be secondary to inadequate nutrition and over-restriction of certain amino acids. In a study by Yannicelli et al. [7], infants diagnosed with MMA were found to grow normally when provided adequate energy, protein and the amino acids isoleucine (ILE), methionine (MET), threonine (THR), and valine (VAL).

Low blood levels of pre-albumin and albumin, indicative of inadequate protein nutrition, has been observed in the patients followed by Kahler et al. [8], as well as this patient. After increasing the protein allowance to $1.2-1.5 \mathrm{~g} / \mathrm{kg} /$ day natural protein and $2.0-$ $2.5 \mathrm{~g} / \mathrm{kg} /$ day of medical food, and increasing daily
Post

- Albumin 4.2

- PreAlbumin 22.9

- Amino acids $\mu \mathrm{mol} / \mathrm{L}$

- Valine

112

- Isoleucine

75

- Leucine

290

- Meth

15

- Arginine

64

- Glycine

407

- Alanine

416

caloric intake to $130 \mathrm{cal} / \mathrm{kg}$, albumin levels normalized, indicating the initial long-term treatment did not provide adequate protein amounts.

Hauser et al. [9], found that equations utilizing FAO/WHO/UNU (1985) recommendations were not a reliable guide for energy requirements of MMA patients and often failed to accurately estimate resting energy expenditures. The study by Yannicelli [6] further demonstrated that adequate linear growth was observed when protein intake was greater than $120 \%$ of the $\mathrm{FAO} / \mathrm{WHO} / \mathrm{UNU}$ recommendations and energy intakes were greater than $100 \%$ of that recommended 
based on age. Protein and energy intake higher than recommended values is suggested in all patients consuming free amino acids as their primary protein source $[10,11]$ secondary to inefficient anabolic utilization $[7,12]$.

L-Carnitine supplementation of approximately 100 $\mathrm{mg} / \mathrm{kg} /$ day is recommended as a prophylactic treatment [6] to bind excess metabolites that accumulate in MMA. The patient in this case responded well to $50 \mathrm{mg} / \mathrm{kg}$ levocarnitine and $50 \mathrm{mg} / \mathrm{kg}$ acetyl-carnitine. The accumulation of acyl-CoA compounds within the mitochondria in MMA depletes carnitine stores and interferes with several metabolic processes. Supplementation with L-carnitine and acetylcarnitine increases excretion of unmetabolized and potentially toxic fatty acids while supplying acetate. Patients with MMA suffer from energy generation deficiencies secondary to inadequate bioavailability of acetyl-CoA. Acetyl-L-carnitine provides both L-carnitine and a source of acetyl-CoA [13] and may be superior to Lcarnitine supplementation in the treatment of MMA. In this case, a 50/50 mixture of L-carnitine/acetyl-carnitine was used although this ratio may need to be further changed in favor of acetyl-carnitine.

In addition to caloric deficiencies, MMA patients also frequently require aggressive treatment with a buffering system. Potassium citrate in the amount used seemed to prevent acidosis and also supply citrate, whose production is compromised in MMA.

Hyperammonemia is often a complication of methylmalonic acidemia due to inhibition of the synthesis of $\mathrm{N}$-acetylglutamate, secondary to depressed activity of $\mathrm{N}$-acetylglutamate synthase by metabolites of the organic acidemias leading to lower levels of carbamylphosphate. Carglumic acid (Carbaglu), a synthetic analog of $\mathrm{N}$-acetylglutamate may need to be added to the treatment of MMA, especially in crisis. Preliminary studies have demonstrated drastic reductions in serum ammonia levels in organic acidemias [14]. Although current studies have been limited, a larger-scale trial of its efficacy in enhancing liver excretion of ammonia in patients with organic acidemias is currently under way [28].

\section{CONCLUSION}

The treatment of inborn errors of metabolism has undergone numerous changes and the recommendations for MMA need to be reassessed. In previous treatment regimens, the severe restriction of protein affected the growth of the patient. Dietary restrictions should be undertaken with caution, with generous allowance of calories to promote weight gain, and severe restriction may not be desirable. Furthermore, with negative outcomes of the disease postponed, it is possible to do such treatments as renal transplant when the patient is in better health. A collaborative study to address nutrient deficiencies is needed.

\section{ABBREVIATION}

MMA = methylmalonic academia

\section{REFERENCES}

[1] Manoli I, Venditti CP. Methylmalonicacidemia 2005-2010. GeneReviews at NCBI Bookshelf. Seattle: University of Washington. Available at: http://www.ncbi.nlm.nih.gov/books/ NBK1231/?report=printable. Accessed October 2, 2011.

[2] Chase DH, Diperna JC, Kalas TA, Johnsosn RW, Naylor EW. Rapid diagnosis of methylmalonic and propionic acidemias: quantitative tandem mass spectrometric analysis of propionylcarnitine in filter-paper blood specimens obtained from newborns. Clin Chem 2001; 47: 2040-2004.

[3] Lee N, Chien Y, Peng S, Huang AC, Liu TT, Wu AS, et al. Brain damage by mild metabolic derangements in methylmalonicacidemia. Pediatr Neurol 2008; 39(5): 325329.

http://dx.doi.org/10.1016/j.pediatrneurol.2008.07.018

[4] Shevell MI, Matiaszuk N, Ledley FD, Rosenblatt DS. Varying neurological phenotypes among mut and mut patients with methylmalonyl CoA mutase deficiency. Am J Med Genet 1993; 45: 619-624.

http://dx.doi.org/10.1002/ajmg.1320450521

[5] Knerr I, Weinhold N, Vockely J, Gibson KM. Advances and challenges in the treatment of branched-chain amino/keto acid metabolic defects. J Inherit Metab Dis 2012; 35(1): 2940. http://dx.doi.org/10.1007/s10545-010-9269-1

[6] Yannicelli S. Nutrition therapy of organic acidaemias with amino acid-based formulas: emphasis on methylmalonic and propionic acidaemia. J Inherit Metab Dis 2006; 29: 281-281. http://dx.doi.org/10.1007/s10545-006-0267-2

[7] Yannicelli S, Acosta PB, Velasquez A, Bock HG, Marriage B, Kurczynski TW, et al. Improved growth and nutritional status in children with methylmalonic or propionic acidemia fed an elemental medical food. Mol Genet Metab 2003; 80: 181188.

http://dx.doi.org/10.1016/j.ymgme.2003.08.012

[8] Kahler SG, Millington DS, Cederbaum SD, Vargas J, Bond LD, Maltby DA, et al. Parenteral nutrition in propionic and methylmalonicacidemia. J Pediatr 1989; 115: 235-241. http://dx.doi.org/10.1016/S0022-3476(89)80071-X

[9] Hauser NS, Manoli I, Graf JC, Sloan J, Venditti CP. Variable dietary management of methylmalonicacidemia: metabolic and energetic correlations. Am J Clin Nutr 2011; 93: 47-56. http://dx.doi.org/10.3945/ajcn.110.004341

[10] Pratt EL, Snyderman SE, Cheung MW, Norton P, Holt LE Jr, Hansen AE, Panos TC. The threonine requirement of the normal infant. J Nutr 1955; 56: 231-251.

[11] Acosta PB, Yannicelli S, Singh RH, Mofidi S, Steiner $r$, DeVicentis $E$, et al. Nutrient intakes and physical growth of children with phenylketonuria undergoing nutritional therapy. J Am Diet Assoc 2003; 103: 1167-1173. 
[12] Hermann ME, Brosicke HG, Koeller M, Monch E, Helge $H$. Dependence of the utilization of phenylalanine-free amino acid mixture on different amounts of single dose ingested. Eur J Pediatr 1994; 153: 501-503.

http://dx.doi.org/10.1007/BF01957005

[13] Scafidi S, Fiskum G, Lindauer SL, Bamford P, Shi D, Hopkins I, McKenna MC. Metabolism of acetyl-L-carnitine for energy and neurotransmitter synthesis in the immature rat brain. $\mathrm{J}$ Neurochem 2010; 114(3): 820-31.

http://dx.doi.org/10.1111/j.1471-4159.2010.06807.x
[14] Levrat V, Forest I, Fouilhoux, Acquaviva C, Vianey-Saban C, Guffon N. Carglumic acid: an additional therapy in the treatment of organic acidurias with hyperammonemia? Orphanet J Rare Dis 2008; 30(3): 2.

[15] Watkins D, Rosenblatt DS. Inborn errors of cobalamin absorption and metabolism. Am J Med Genet Part C Semin Med Genet 2011; 157: 33-44.

http://dx.doi.org/10.1002/ajmg.c.30288 